\title{
Influenza A viruses of avian origin circulating in pigs and other mammals
}

\author{
Kinga Urbaniak ${ }^{\bowtie}$, Andrzej Kowalczyk and Iwona Markowska-Daniel \\ Department of Swine Diseases, National Veterinary Research Institute, Puławy, Poland
}

\begin{abstract}
Influenza A viruses (IAVs) are zoonotic agents, capable of crossing the species barriers. Nowadays, they still constitute a great challenge worldwide. The natural reservoir of all influenza A viruses are wild aquatic birds, despite the fact they have been isolated from a number of avian and mammalian species, including humans. Even when influenza A viruses are able to get into another than waterfowl population, they are often unable to efficiently adapt and transmit between individuals. Only in rare cases, these viruses are capable of establishing a new lineage. To succeed a complete adaptation and further transmission between species, influenza A virus must overcome a species barrier, including adaptation to the receptors of a new host, which would allow the virus-cell binding, virus replication and, then, animal-toanimal transmission. For many years, pigs were thought to be intermediate host for adaptation of avian influenza viruses to humans, because of their susceptibility to infection with both, avian and human influenza viruses, which supported hypothesis of pigs as a "mixing vessel". In this review, the molecular factors necessary for interspecies transmission are described, with special emphasis on adaptation of avian influenza viruses to the pig population. In addition, this review gives the information about swine influenza viruses circulating around the world with special emphasis on Polish strains.
\end{abstract}

Key words: influenza A viruses, hemagglutinin, neuraminidase

Received: 29 May, 2014; revised: 21 July, 2014; accepted: 25 August, 2014; available on-line: 04 September, 2014

\section{INTRODUCTION}

Avian influenza A viruses belong to the family $O r$ thomyxoviridae. They are classified into subtypes on the basis of two surface glycoproteins: hemagglutinin (HA) and neuraminidase (NA) (Kalthoff et al., 2010; Kaplan et al., 2013). All of sixteen HA (H1-H16) and nine NA (N1-N9) subtypes have been isolated from aquatic birds (Kim et al., 2009; Imai \& Kawaoka, 2012; Kaplan et al., 2013), which are their natural reservoir. However, viruses of avian origin have been isolated from a number of mammalian species, including humans, pigs, horses, dogs, cats and water mammals (Kuiken et al., 2004; Mänz et al., 2013).

The worldwide spread of IAVs results from the migration of waterfowl, when, in occasional cases of domestic birds and mammals infection, self-limiting or sustained epidemics or even pandemics arise (Reperant et al., 2012; Kaplan et al., 2013). The infection of different mammalian species by avian IAVs is possible due to the lack of immunity to these strains (Mänz et al., 2013), but only in rare cases a new virus lineage is established.

To succeed cross-species transmission and full adaptation of avian IAV to another species, several barriers need to be overcome (Reperant et al., 2012). In the past, a few such cases were recorded, for example, the 'Spanish' pandemic of 1918, the Eurasian classical swine influenza virus lineage, H3N8 influenza viruses in horses, and distinct lineage of IAVs in bats (Mänz et al., 2013).

\section{IAV HOST SWITCH}

Despite significant research, the mechanisms of overcoming species barriers by avian influenza virus are not completely understood (Taubenberger \& Kash, 2010). The successful transmission between species depends on both, host and virus factors, and some period of adaptation of the virus to the new species. For example, an introduction of an avian $\mathrm{H} 1 \mathrm{~N} 1$ virus to pigs in continental Europe in 1979 usually caused subclinical infection of pigs (period of adaptation), whereas emerged fully adapted 'avian-like' swine H1N1 virus from continental Europe to Great Britain in 1992 with naïve pig population could explain the rapid spread of the disease (Brown, 2000). Human or other mammal infection caused by avian IAV may be dead-end infection or lead to a new lineage (Taubenberger \& Kash, 2010).

\section{AVIAN IAV IN PIGS}

Domestic pigs are susceptible to the infection with IAV (Kaplan et al., 2013), and have been considered as an adaptive link between avian and mammalian hosts. Pigs express both, avian and human types of sialo-receptors, which results in the susceptibility to infection with avian and human IAVs (Kida et al., 1994; Kalthoff et al.,

e-mail: kinga.urbaniak@piwet.pulawy.pl

Abbreviations: IAV, influenza A virus; $\mathrm{HA}$, haemagglutinin; $\mathrm{H} 1-\mathrm{H} 16$, haemagglutinin subtype 1-16; NA, neuraminidase; N1-N9, neuraminidase subtype 1-9; NP, nucleoprotein; M gene, matrix gene; NS gene, non-structural gene; PB1, basic protein 1; PB2, basic protein 2; PA, acid protein; RNA, ribonucleic acid; RNP, ribonucleoprotein; $\mathrm{pH}$, potential hydrogen; Siaa2,6Gal, sialic acid linked to galactose by a2,6-linkage; Siaa2,3Gal, sialic acid linked to galactose by a2,3linkage; HP, high pathogenic; H1N1pdm09, the 2009 H1N1 pandemic viruses; swine PCh73-like lineage, swine adapted A/Port Chalmers/1/73-like human influenza viruses; OIE, The World Organization for Animal Health; $N$, asparagine; $D$, aspartic acid; $R$, arginine; E, glutamic acid; Q, glutamine; G, glycine; L, leucine; K, lysine; $M$, methionine; $P$, proline; $S$ serine; $T$, threonine; $V$, valine. 
2010; Imai \& Kawaoka, 2012). The possibility of infection pigs with swine/avian/human IAVs constitutes the basis of swine as the 'mixing vessel' hypothesis put forward in the late 1980's (Ma et al., 2009). Firstly, it has been reported that epithelial cells of pigs trachea express a sufficient number of both types of receptors (Imai \& Kawaoka, 2012). However, further studies have shown that on the tracheal epithelia of pigs is more Sia $2,6 \mathrm{Gal}$ (human) than Sia 2,3Gal (avian) receptors (Nelli et al., 2010; Taubenberger \& Kash, 2010; Thongratsakul et al., 2010; Van Poucke et al., 2010; Imai \& Kawaoka, 2012). Nevertheless, the cases of isolation various subtypes of avian influenza virus in swine population are evidenced worldwide (Brown, 2000; Taubenberger \& Kash, 2010). Most of these cases have been self-restricted and did not led to the introduction of novel fully adapted to swine IAVs of avian origin. These data, together with the evidence of restricted replication and transmission of avian IAV in pigs (Kalthoff et al., 2010; Taubenberger \& Kash, 2010), tend to reflect the role of swine as the "mixing vessel" and provide further questions regarding the mechanisms of overcoming the avian-mammalian barrier (Taubenberger \& Kash, 2010).

An important exception is the European swine H1N1 virus introduced to pigs from avian influenza virus population. This virus, antigenically closely related to H1N1 viruses isolated from wild ducks in 1976-1977, has become well-established and has been circulating in pigs since late 1970's till now (Brown, 2000; Dunham et al., 2009; Ma et al., 2009). It played a crucial role in the emergence of the H1N1 pandemic in 2009 (Taubenberger \& Kash, 2010). Since 1979, the avian-like swine H1N1 virus demonstrating a selective advantage replaced in Europe the classical swine H1N1 virus previously circulating in pigs. Ever since 1993, when an independent introduction of a H1N1 virus of avian origin to pigs in China was detected, this virus has been co-circulating with classical swine H1N1 viruses in pigs in south-east Asia. Based on phylogenetic analysis of the genes of these avian-like H1N1 viruses, it appears that they form an Asian sub-lineage of the Eurasian avian lineage. In addition, in Asia, since the 1970's, some of H3N2 viruses isolated from pigs have been fully 'avian-like' and have been apparently introduced from ducks (Brown, 2000). Also, different avian viruses (H4N6, H1N1 and H3N3) have been transmitted to Canadian pigs (Karasin et al., 2000; Karasin et al., 2004), but currently they have not been detected in swine population (Ma et al., 2009). More recently, the introduction of H9N2 viruses from poultry to pigs in Southeast Asia has occurred (Brown, 2000), but they also do not fully adapt to swine (Xu et al., 2004; Cong et al., 2008; Shi et al., 2008; Yu et al., 2008).

To better understand the mechanisms of the adaptation of avian IAVs to pig, many different experimental studies were conducted. For example, Kida et al. (1994) performed an experimental infection of pigs with H1H13 avian influenza viruses. The susceptibility of pigs to different subtypes of avian IAV was also confirmed previously by Hinshaw et al. (1981). It seems that for an efficient overcoming the species barriers and full adaptation to pig, certain genetic changes in IAVs need to be introduced (De Vleeschauwer et al., 2009; Markowska-Daniel et al., 2012a). In the past, swine-adapted IAVs have also been connected to zoonotic infections in humans. Between 1958 and 2005, 37 cases were documented (Myers et al., 2007). For example, the infection of soldiers at FortDix in New Jersey with classical swine
H1N1 in 1976 with one fatal case has been described (Taubenberger \& Kash, 2010).

\section{AVIAN IAV IN OTHER SPECIES}

Apart from humans and pigs, also other mammalian, like horses and dogs, can be infected with avian IAVs. In both species, transmission of low pathogenic avian IAV results in establishing a new virus lineages. Up till now, there has been no information about transmission of these viruses to humans. The occasional epidemics with avian IAVs have occurred in mink, harbour seals and whales, respectively (Reperant et al., 2009; Reperant et al., 2012). Among high pathogenic (HP) avian IAVs, only H5N1 was identified in wild range of wild and terrestrial birds and mammals. Besides a direct exposure to avian influenza viruses, carnivorous animals can be infected by consuming meat from infected birds. The infection with HP H5N1 via the intestinal tract was experimentally confirmed for cats, ferrets, red foxes, mice and hamsters (Reperant et al., 2012).

\section{SWINE IAV}

It has been suggested that all mammalian IAV strains originate from avian IAVs (Webster et al., 1992; Taubenberger \& Kash, 2010; Reperant et al., 2012). All IAVs established in pig population are of the H1N1, H1N2 or H3N2 subtypes. However, multiple lineages distinguish viruses from different continents, countries and regions (Vincent et. al., 2014). The 2009 H1N1 pandemic virus (H1N1pdm09) outbreaks in pigs were preceded by human influenza-like diseases and were reported in many countries. Between April 2009 and September 2010, The World Organization for Animal Health (OIE) received information on occurrence of the H1N1pdm09 from 25 countries. In 2010 the disease was generally accepted to be circulating commonly in pigs (Vincent et. al., 2014). In North America pig population different IAV strains are circulating. By 1998, when the triple-reassortant H3N2 virus adapted to pig, the classical swine H1N1 virus was relatively stable. After that, a variety of $\mathrm{H} 3 \mathrm{~N} 2$ and classical H1N1 reassortans emerged. Since 2005, H1N1 and H1N2 viruses derived from human seasonal IAV have become established in pig herds. And since 2009, H1N$1 \mathrm{pdm} 09$ has emerged in the swine population (Vincent et. al., 2014). In Asia, like in North America, different swine IAV lineages are co-circulating. Classical swine $\mathrm{H} 1 \mathrm{~N} 1$ viruses, H1N2 viruses (N2 of human origin, other genes from the classical swine virus origin), human-like H3N2 viruses, avian-like H1N1 viruses (not descendant of European avian-like), European H3N2 and H1N1 viruses, North America triple reassortant viruses, H1N1pdm09 virus and its reassortants in Asian pig population has been detected (Vincent et. al., 2014). In the European swine population the circulation of the avian-like H1N1, human-like H1N2 and human-like H3N2 viruses has been reported. The avian-like H1N1 replaced the classical H1N1 swine virus around 1979. After pandemic in 1968, human-like H3N2 emerged in pigs and in the mid-1980s reassorted with the avian-like H1N1 virus. The human-like H1N2 virus has become established in pigs in Great Britain in 1994 and subsequently spread to other European countries. After pandemic in 2009, also the continued circulation of H1N1pdm09 virus has been detected (Vincent et. al., 2014).

In Poland, between 2000 and 2008, in 20 out of 30 tested farms $41 \mathrm{SIV}$ strains were isolated from animals 


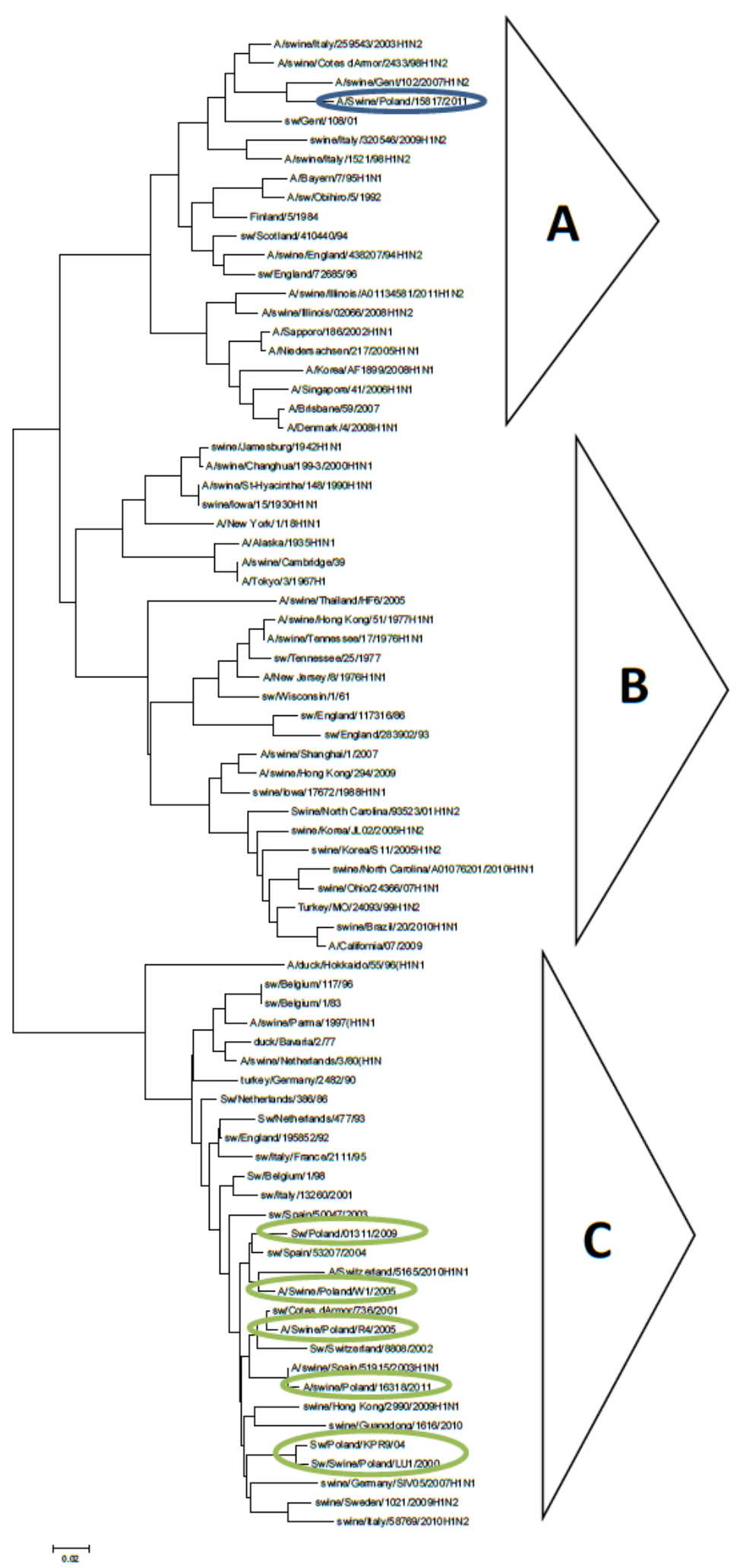

Figure 1. A neighbor-joining phylogenetic tree for nucleotide sequences of the HA1 gene of influenza viruses selected to be representative of HA gene segments in relevant hosts.

Group A - IAVs with the HA gene of European human-like H1N2 virus; group B IAVs with the HA gene of H1N1pdm09 virus; group C - IAVs with the HA gene of European avian-like H1N1 virus. Polish SIV isolates of H1N2 and H1N1 subtype are marked with a blue and green ovals, respectively. demonstrating symptoms of influenza-like respiratory disorders. Thirty-nine isolates were subtyped as $\mathrm{H} 1 \mathrm{~N} 1$ and 2 as H3N2. Those two SIV strains represent the initial, newly emerged H3N2 subtype detected in Poland (Kowalczyk et al., 2010). The parallel evolution of the prevalent Spanish, Belgium, Italian and Polish strains occurred, which may suggest the that virus spread through transport of animals. Phylogenetic analyses proved that the newer swine $\mathrm{H} 3 \mathrm{~N} 2$ viruses gradually evolved from the early swine-adapted A/Port Chalmers/1/73-like human influenza viruses (swine PCh73-like lineage) (de Jong et al., 2007) (Fig. 2).

The Neighbour-Joining tree of the HA gene shows three highly significant clusters that correspond to EU H1N2 SIVs with a human-like H1, EU $\mathrm{H} 1 \mathrm{~N} 1 \mathrm{SIVs}$ with an avian-like $\mathrm{H1}$, and the H1N1pdm09 clades. Polish strains H1N1 were mostly similar to each other, but also indicated high identity values with strains from the West Europe, the probable source of their progenitor virus. Phylogenetic comparisons of their HA1 gene confirmed that they are closely related to the HA genes of avian-like $\mathrm{H} 1 \mathrm{~N} 1$ viruses circulated in Europe, and form separate clad (grouped in the branch C) (Fig. 1). The most of Polish H1N1 strains were closely related to Cotes d'Armor/1488/99 (99.5\% with Pol/RU1/02), Spain/53207/2004 (99.5\% with Pol/J2/04) and Switzerland/8808/2002 (97.9\% homology with $\mathrm{Pol} / \mathrm{RU} 1 / 02)$.

In 2011 the first Polish H1N2 strain (A/Swine/Poland/15817/2011) was isolated. This virus has the highest homology to $\mathrm{H} 1 \mathrm{~N} 2$ viruses circulating in Europe (95\% with A/Swine/ Gent/102/2007, A/Swine/Cotes d'Armor/2433/98, and A/Swine/Italy/25943/98) (Fig. 1). Phylogenetic analysis revealed that Polish H1N2 is located in the phylogenetic tree in the clade of the human swine lineage marked as a group A (Kowalczyk et al., 2012). The highest nucleotide similarity of the HA1 Polish H1N1 virus with H1N2 strain was observed for A/Swine/Poland/01311/2009 (66.9\%) (Markowska-Daniel et al., 2013b). An external gene of Polish H1N2 isolate indicates that it is most similar to a subgroup, which evolved at the beginning of 1990's and formed a new antigenic subcluster with the novel European and the Asian human influenza viruses and SIV isolates $\mathrm{H} 1 \mathrm{~N} 2$ and H3N2 from around year 2000 (Kowalczyk et al., 2012).

Since the pandemic emergence in 1968, human influenza virus H3N2 subtype occurred in an infected pig frequently. Serological examination indi- 


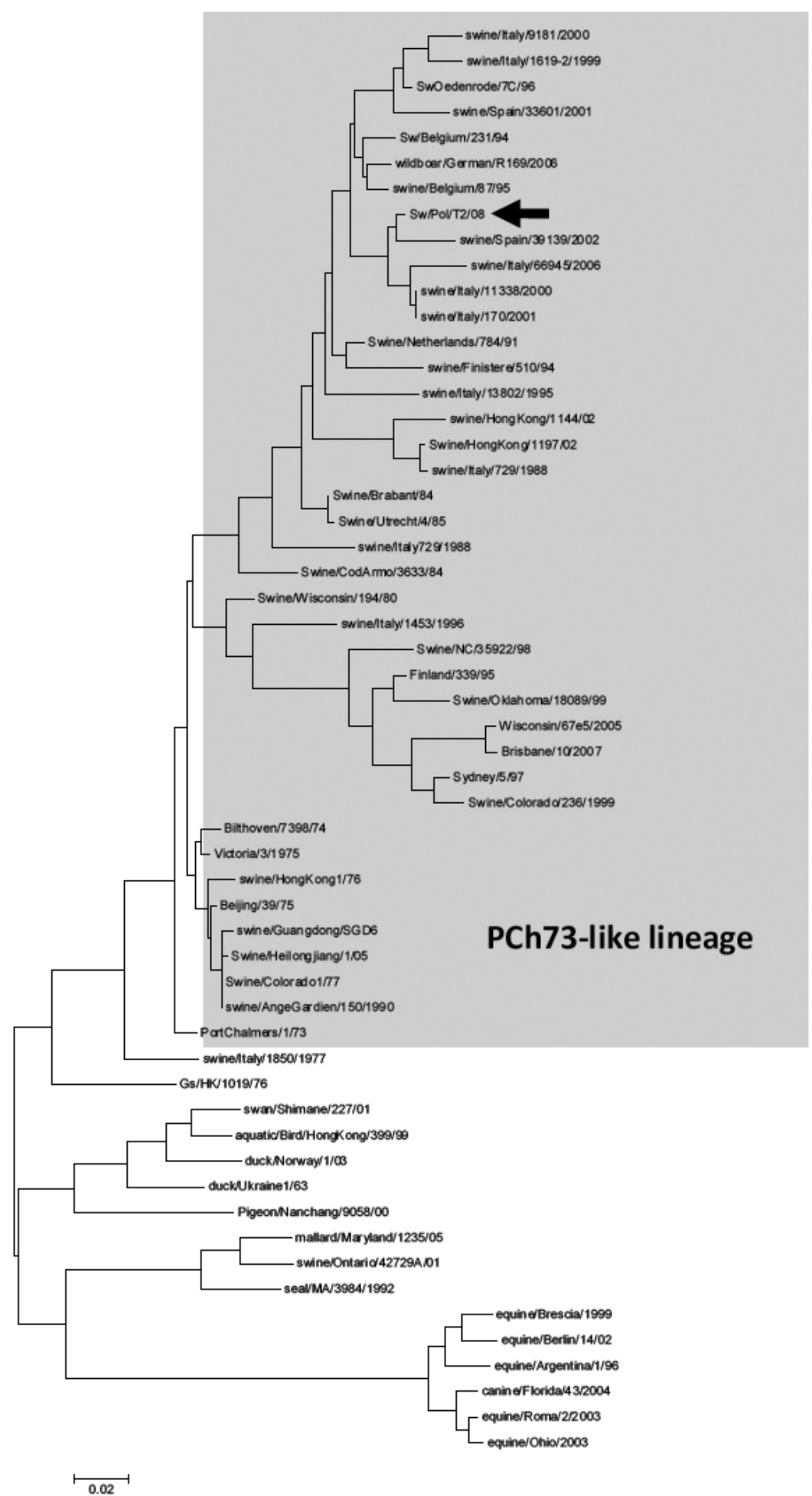

Figure 2. Phylogenetic tree for HA3 of swine influenza viruses and human, avian and equine reference strains.

H3N2 SIV strain isolated in Poland is marked with black arrow. The scale bar represents approximately $2 \%$ nucleotides changes between close relation. In the grey box SIV named as the PCh73-like lineage group were located.

cated the introduction of an A/Port Chalmers/1/73-like human influenza virus into the pig population in 1974 and its evolution created new phylogenetic cluster called PCh73-like (de Jong et al., 2007). The main European genetic group is the A/Port Chalmers/1/73-like Eurasian swine H3N2 lineage. Within PCh73-like lineage, Polish isolate $\mathrm{H} 3 \mathrm{~N} 2$ is the most similar to a subgroup, which evolved at the beginning of 1990's and formed new antigenic subcluster. Polish isolate $\mathrm{Sw} / \mathrm{Pol} / \mathrm{T} 2 / 2008$ has the highest similarity with A/Swine/Italy/11338/2000 (96.8\%), A/Swine/Spain/739139/2002 (97.5\%) and A/ Swine/Belgium/87/95 (96.9\%). It is the most distanced from vaccine used in human population in Europe (A/ Port Chalmers/1/73 - 89.3\%) and USA (A/Wiscon- 
Table 1. Mutations of IAV proteins influencing on the adaptation.

\begin{tabular}{|c|c|c|}
\hline & \multicolumn{2}{|r|}{ Adaptive mutations } \\
\hline & Avian-like & Mammalian- like \\
\hline HA1 & E190; D225 & D190; G225 \\
\hline $\mathrm{HA} 2$ & \multirow{2}{*}{ Q226; G228 } & \multirow{2}{*}{ L226; S228 } \\
\hline HA3 & & \\
\hline PB2 & E627; D701 & $\begin{array}{l}\text { K627; N701; } \\
\text { S509 and R591 (SR polymorphism) }\end{array}$ \\
\hline PA & L336; T552; K615 & M336; S552; N615 \\
\hline PB1 & L473; L598 & V473; P598 \\
\hline
\end{tabular}

$\sin / 67 e 5 / 2005$ - 82.1\%) (Fig. 2) (Kowalczyk et al., 2010).

After emerging of $\mathrm{H} 1 \mathrm{~N} 1 \mathrm{pdm} 09$ virus in human population several incursions into domestic pig herds have been reported. In 2012 the first H1N1pdm09 viruses emerged from clinical swine influenza outbreaks in Poland. The phylogenetic analysis of the HA and NA genes shows that these Polish H1N1pdm09 viruses can be segregated into one lineage, including the pandemic strain A/California/04/2009 and other human strains circulated since 2009 in Europe, Asia and North America. Polish isolate A/swine/Poland/15620/12 has the highest homology (99\%) with human strain A/Warsaw/ INS20/2011, whereas A/swine/Poland/03195/2012 is more similar to earlier isolates with the highest nucleotide relation to A/Singapore/KK24/2010 (98.8\%), and to the majority of human viruses isolated in Asia in 2009-2010 (Markowska-Daniel et al., 2013a). Additionally, based on the results of serological examination, the co-circulation of SIV of different subtypes in Polish pig herds was evidenced (Markowska-Daniel et al., 2012b).

\section{BARRIERS FOR CROSS-SPECIES TRANSMISSION}

The barriers that need to be overcome to introduce avian IAV to mammalian species can be divided into three groups: barriers of transmission between species, virus-cell binding barriers and animal-to-animal transmission barriers.

In the transmission between wild waterfowl and mammals, several factors such as the occurrence of IAV infection in wild birds, contact between birds and swine, population sizes and densities, habitats restricted by geography, environment and behaviour, determine the possibility of occurrence of zoonotic infections with IAVs. The intensive production and consumption of pigs and other livestock as well as improper biosecurity of the farms may increase the probability of their contact with wild birds and transmission of IAVs (Reperant et al., 2012). Influenza virus in wild water birds population is transmitted by faecal-oral route, whereas in mammals respiratory transmission occurs (Reperant et al., 2009; Reperant et al., 2012). Thus, the ability of avian influenza viruses to infect the host via droplet or aerosol, should be considered as an important factor in transmission (Reperant et al., 2012).

After entering into a new host, virus needs to cross virus-cell barriers, including virus attachment to host cell, virus fusion with cell membranes, virus replication and release of progeny virions. The virus binding depends on the presence and accessibility of receptors recognized by avian IAVs. Despite the presence of receptors, secreted mucus and the ciliated epithelium can preclude the virus attachment. When the virus is already bound to the host cell, the next step is the membrane fusion, which occurs after cleavage the HA protein into two polypeptide chains by host proteases. These proteases that catalyse HA cleavage are necessary for initiation of the infection (Reperant et al., 2012). The virus entry is followed by its replication. The low $\mathrm{pH}$ causes a release of ribonucleoprotein (RNP) complexes into the cell cytoplasm, which permits their transport into the nucleus. At this stage, both, the transport and compatibility of the proteins of RNP, are factors important in overcoming the species barrier (Baigent \& McCauley, 2003). The last step is progeny virions assembly and their release from the infected cell. The NA and its sialidase activity play a major role in a virion release (Reperant et al., 2012). The efficient virus entry into and release from host cells depends on the balance between HA and NA activities, essential to introduce IAV to a new host (Wagner et al., 2002). In order to fully adapt the IAV to a novel host species, the virus needs to acquire the ability of spread among individuals and to be maintained in a susceptible host population (Reperant et al., 2012).

\section{ADAPTIVE MUTATION IN HA OF IAV}

The virulence, pathogenicity, host adaptation and transmissibility of IAVs are probable independent characteristics related with different mutations (Taubenberger \& Kash, 2010)

Genes with the highest rate of change are these encoding the surface glycoprotein HA and NA (Brown, 2000).

The HA glycoprotein is responsible for virus binding to receptors (sialic acid) on the host cell surface (Oshansky et al., 2011), which initiates fusion of the viral envelope with the host cell membrane (Imai \& Kawaoka, 2012). The sialic acid can be linked to galactose by $\alpha 2,6$-linkages (Sia $\alpha 2,6 \mathrm{Gal})$ or by $\alpha 2,3$-linkages (Sia 2 ,$3 \mathrm{Gal})$. The receptor Sia $2,6 \mathrm{Gal}$ is preferred by human IAVs, whereas second with Sia $2,3 \mathrm{Gal}$, with high expression in the gastrointestinal tract of aquatic fowl, is recognized by HA of avian IAVs (Shinya et al., 2006; Stevens et al., 2006; Taubenberger \& Kash, 2010; Van Poucke et al., 2010; Oshansky et al., 2011; Imai \& Kawaoka, 2012). The HA membrane protein is a major determinant for crossing the species barrier (Glaser et al., 2005; Ma et al., 2009). The adaptation of avian influenza viruses to mammalian hosts is connected with a switch in HA ability to bind Sia 2,6Gal instead of Sia 2,3Gal (Oshansky et al., 2011; Imai \& Kawaoka, 2012).

The HA glycoprotein recognized sialic acid via receptor binding domain formed by the 190-helix at the top and two loops: 220-loop and 130-loop at the edges of the globular head. Mutations in amino acid sequence in and around this domain dramatically change the binding preference of influenza viruses to receptors. However, among the different HA subtypes, amino acids defining receptor-binding specificity may vary (Imai \& Kawaoka, 2012), and the mutations support the adaptation of avian IAV to human or swine. For example, in H1 E190D and D225G mutations are necessary for binding to Sian2,6Gal (Glaser et al., 2005; Stevens et al., 2006; Imai \& Kawaoka, 2012), whereas in the case of H2 and H3, the substitutions of Q226L and G228S are critical for the shift from Sia 2,3Gal to Sia 2,6Gal recognition (Table 1) (Liu et al., 2009; Xu et al., 2010; Imai \& Kawaoka, 
2012). However, some avian IAVs with H7N2, H7N3 and H9N2 subtypes, despite showing enhanced binding to Sia 2,6Gal, caused only occasional zoonotic infection in humans. Therefore, it is clear that for the host switching, enriched recognition of human type receptors is not sufficient by itself (Taubenberger \& Kash, 2010).

\section{ADAPTIVE MUTATION IN IAV POLYMERASE}

The polymerase mediates transcription and replication of the viral genome, and plays also a crucial role in adjusting host-range specificity (Mehle \& Doudna, 2009). Species-specific activity of the polymerase is primarily regulated by amino acid at position 627 of the PB2 subunit (Mehle \& Doudna, 2009; Mänz et al., 2013). Mutation at this position enables to omit species restrictions. Glutamic acid (E627) at position 627 predominates virus replication in avian cells, whereas lysine (K627) at this position is found in PB2 in almost every human isolates (Mehle \& Doudna, 2009). The mutation E627K had enriched activity of polymerase, and in some cases, the pathogenicity and mortality in mammals (Li et al., 2009; Mehle \& Doudna, 2009; Steel et al., 2009). Substitution of glutamic acid by lysine moderately enhanced IAV replication in pigs that are thought to be intermediate host for adaptation of avian IAVs to humans (Mehle \& Doudna, 2009).

However, all of isolates of the H1N1pdm09 virus responsible for the last influenza pandemic in humans have the avian signature (E627) in the PB2 protein. Despite the lack of lysine at amino acid 627, this virus replicates and causes disease in humans and animal models (Fraser et al., 2009; Itoh et al., 2009; Maines et al., 2009; Munster et al., 2009). In this case, it is connected to mutations, termed the serine-arginine (SR) polymorphism. In amino acid sequence of PB2 subunit, at positions 590 and 591, serine (S) and arginine (R) are present, respectively. The SR polymorphism mainly decrease the restriction related with PB2 E627, because the presence of S590 and R591 did not increase polymerase activity with amino acid substitution E627K (Mehle \& Doudna, 2009). Both, mutation at 627 position and the SR polymorphism, may function through stabilizing a positively charged PB2 surface, which means that this region is involved in interactions with unspecified host specific factors (Mehle \& Doudna, 2008). Other identified change in PB2 structure, that influences host range and improves replication and transmission in mammalian systems (Gabriel et al., 2005; Li et al., 2005; Gabriel et al., 2007; Mehle \& Doudna, 2009; Steel et al., 2009), is $\mathrm{D} 701 \mathrm{~N}$ mutation in region responsible for nuclear localization (Tarendeau et al., 2007; Gabriel et al., 2008; Taubenberger \& Kash, 2010). This mutation can partially offset the lack of lysine at PB2-627 position in avian viruses (Steel et al., 2009). Regarding the PA subunit, different mutations at various positions have been identified (336M, 552S, 615N) (Mänz et al., 2013), whereas in PB1 subunit, only substitutions at positions 473 and 598 contributed to the improvement of avian polymerases activity in mammalian cells ( $\mathrm{Xu}$ et al., 2012) (Table 1).

\section{REMAINING IAV PROTEINS}

The NA is a surface glycoprotein that is responsible for releasing progeny viruses by removing them from the surface of infected cells and subsequently for spreading the IAV (Ma et al., 2009; Yan \& Wu, 2010). This protein also affects the species specificity of IAVs. For example, when avian IAV is introduced to the human population, the cleavage activity of the avian NA increases towards Sia 2,6Gal receptors (Ma et al., 2009). The NP, M, NS genes also take part in host range specificity of influenza viruses (Ma et al., 2009; Taubenberger \& Kash, 2010; Mänz et al., 2013). Their contribution is based on particular gene constellation and interactions with host cell components in cytoplasm and nucleus (Ma et al., 2009).

\section{CONCLUSIONS}

Avian IAVs mainly affect wild and terrestrial birds. However, certain subtypes have the potential to directly infect other species. To fully adapt, infect and spread in a novel host population, avian IAVs need to overcome a set of barriers. To deal with these barriers, certain adaptive mutations allowing avian IAVs to switch host range need to occur. Most of them involve specific mechanisms of adaptation that can be detected, both, genetically and phenotypically. The variety of avian IAVs combined with the high ability of adaptation constitutes the main risk factor for crossing the species barriers. An enhanced potential of avian IAV may result in efficient transmission in the mammalian species, like for example the European avian-like swine H1N1 virus, which still dominates in the Polish pig population. To conclude, in order to identify precursor viruses of potential pandemics, an active surveillance and collecting of avian IAVs isolates from different species are crucial.

\section{Acknowledgements}

Preparation of this paper was supported by FLUPIG Project No 258084 founded by EC FP7.

\section{REFERENCES}

Baigent SJ, McCauley JW (2003) Influenza type A in humans, mammals and birds: determinants of virus virulence, host range and interspecies transmission. Bioessays 25: 657-671.

Brown IH (2000) The epidemiology and evolution of influenza viruses in pigs. Vet Microbiol 74: 29-46.

Cong YL, Wang CF, Yan CM, Peng JS, Jiang ZL, Liu JH (2008) Swine infection with H9N2 influenza viruses in China in 2004. Virus Genes 36: 461-469.

De Vleeschauwer A, Van Poucke S, Braeckmans D, Van Doorsselaere J, Van Reeth K (2009) Efficient transmission of swine-adapted but not wholly avian influenza viruses among pigs and from pigs to ferrets. I Infect Dis 200: 1884-1892.

Dunham EJ, Dugan VG, Kaser EK, Perkins SE, Brown IH, Holmes EC, Taubenberger JK (2009) Different evolutionary trajectories of European avian-like and classical swine H1N1 influenza A viruses. J Virol 83: 5485-5494.

Fraser C, Donnelly CA, Cauchemez S, Hanage WP, Van Kerkhove MD, Hollingsworth TD, Griffin J, Baggaley RF, Jenkins HE, Lyons EJ, Jombart T, Hinsley WR, Grassly NC, Balloux F, Ghani AC, Ferguson NM, Rambaut A, Pybus OG, Lopez-Gatell H, AlpucheAranda CM, Chapela IB, Zavala EP, Guevara DM, Checchi F, Garcia E, Hugonnet S, Roth C; WHO Rapid Pandemic Assessment Collaboration (2009) Pandemic potential of a strain of influenza A (H1N1): Early findings. Science 324: 1557-1561.

Gabriel G, Abram M, Keiner B, Wagner R, Klenk HD, Stech J (2007) Differential polymerase activity in avian and mammalian cells determines host range of influenza virus. J Virol 81: 9601-9604.

Gabriel G, Dauber B, Wolff T, Planz O, Klenk HD, Stech J (2005) The viral polymerase mediates adaptation of an avian influenza virus to a mammalian host. Proc Natl Acad Sci U S A 102: 18590-18595.

Gabriel G, Herwig A, Klenk HD (2008) Interaction of polymerase subunit PB2 and NP with importin alpha1 is a determinant of host range of influenza A virus. PLoS Pathog 4: e11.

Glaser L, Stevens J, Zamarin D, Wilson IA, Garcia-Sastre A, Tumpey TM, Basler CF, Taubenberger JK, Palese P (2005) A single amino acid substitution in 1918 influenza virus hemagglutinin changes receptor binding specificity. J Virol 79: 11533-11536. 
Hinshaw VS, Webster RG, Easterday BC, Bean WJ Jr (1981) Replication of avian influenza $\mathrm{A}$ viruses in mammals. Infect Immun 34: 354-361.

Imai M, Kawaoka Y (2012) The role of receptor binding specificity in interspecies transmission of influenza viruses. Curr Opin Virol 2: 160-167.

Itoh Y, Shinya K, Kiso M, Watanabe T, Sakoda Y, Hatta M, Muramoto Y, Tamura D, Sakai-Tagawa Y, Noda T, Sakabe S, Imai M, Hatta Y, Watanabe S, Li C, Yamada S, Fujii K, Murakami S, Imai H, Kakugawa S, Ito M, Takano R, Iwatsuki-Horimoto K, Shimojima M, Horimoto T, Goto H, Takahashi K, Makino A, Ishigaki H, Nakayama M, Okamatsu M, Takahashi K, Warshauer D, Shult PA, Saito R, Suzuki H, Furuta Y, Yamashita M, Mitamura K, Nakano K, Nakamura M, Brockman-Schneider R, Mitamura H, Yamazaki M, Sugaya N, Suresh M, Ozawa M, Neumann G, Gern J, Kida H, Ogasawara K, Kawaoka Y (2009) In vitro and in vivo characterization of new swine-origin H1N1 influenza viruses. Nature 460: 1021-1025.

de Jong JC, Smith DJ, Lapedes AS, Donatelli I, Campitelli L, Barigazzi G, Van Reeth K, Jones TC, Rimmelzwaan GF, Osterhaus ADME, Fouchier RAM (2007) Antigenic and genetic evolution of swine influenza A (H3N2) viruses in Europe. J Virol 81: 4315-4322.

Kalthoff D, Globig A, Beer M (2010) (Highly pathogenic) avian influenza as a zoonotic agent. Vet Microbiol 140: 237-245.

Kaplan BS, Webby RJ (2013) The avian and mammalian host range of highly pathogenic avian H5N1 influenza. Virus Res 178: 3-11.

Karasin AI, Brown IH, Carman S, Olsen CW (2000) Isolation and characterization of $\mathrm{H} 4 \mathrm{~N} 6$ avian influenza viruses from pigs with pneumonia in Canada. J Virol 74: 9322-9327.

Karasin AI, West K, Carman S, Olsen CW (2004) Characterization of avian $\mathrm{H} 3 \mathrm{~N} 3$ and $\mathrm{H} 1 \mathrm{~N} 1$ influenza $\mathrm{A}$ viruses isolated from pigs in Canada. I Clin Microbiol 42: 4349-4354.

Kida H, Ito T, Yasuda J, Shimizu Y, Itakura C, Shortridge KF, Kawaoka Y, Webster RG (1994) Potential for transmission of avian influenza viruses to pigs. J Gen Virol 75: 2183-2188.

Kim JK, Negovetich NJ, Forrest HL, Webster RG (2009) Ducks: the "Trojanhorses" of H5N1 influenza. Influenza Other Respi Viruses 3: 121-128.

Kowalczyk A, Markowska-Daniel I (2010) Phylogenetic analysis of swine influenza viruses isolated in Poland. Pol J Vet Sci 13: 37-44.

Kowalczyk A, Urbaniak K, Markowska-Daniel I (2012) Phylogenetic analysis of the first Polish H1N2 swine influenza virus isolate. Bull Vet Inst Pulawy 56: 419-424.

Li J, Ishaq M, Prudence M, Xi X, Hu T, Liu Q, Guo D (2009) Single mutation at the amino acid position 627 of PB2 that leads to increased virulence of an $\mathrm{H} 5 \mathrm{~N} 1$ avian influenza virus during adaptation in mice can be compensated by multiple mutations at other sites of PB2. Virus Res 144: 123-129.

Li Z, Chen H, Jiao P, Deng G, Tian G, Li Y, Hoffmann E, Webster RG, Matsuoka Y, Yu K (2005) Molecular basis of replication of duck H5N1 influenza viruses in a mammalian mouse model. $J$ Virol 79: 12058-12064.

Liu J, Stevens DJ, Haire LF, Walker PA, Coombs PJ, Russell RJ, Gamblin SJ, Skehel JJ (2009) Structures of receptor complexes formed by hemagglutinins from the Asian Influenza pandemic of 1957. Proc Natl Acad Sci U S A 106: 17175-17180.

Ma W, Lager KM, Vincent AL, Janke BH, Gramer MR, Richt JA (2009) The role of swine in the generation of novel influenza viruses. Zoonoses Public Health 56: 326-337.

Maines TR, Jayaraman A, Belser JA, Wadford DA, Pappas C, Zeng H, Gustin KM, Pearce MB, Viswanathan K, Shriver ZH, Raman R, Cox NJ, Sasisekharan R, Katz JM, Tumpey TM (2009) Transmission and pathogenesis of swine-origin 2009 A(H1N1) influenza viruses in ferrets and mice. Science 325: 484-487.

Mänz B, Schwemmle M, Brunotte L (2013) Adaptation of avian influenza A virus polymerase in mammals to overcome the host species barrier. J Virol 87: 7200-7209.

Markowska-Daniel I, Pomorska-Mól M, Kowalczyk A, Urbaniak K, Kwit K, Pejsak Z (2012a) In vivo adaptation of wholly avian influenza virus to the pig. Mat. 22 IPVS Congress Korea, p 432.

Markowska-Daniel I, Kwit K, Urbaniak K, Kowalczyk A (2012b) Serological evidence of co-circulation of different subtypes of swine influenza virus in Polish pig herds. Bull Vet Inst Pulawy 56: 425-429.

Markowska-Daniel I, Urbaniak K, Porowski M, Karbowiak P, Kowalczyk A, Kozak E, Pejsak Z (2013a) Emergence of the pandemic H1N1 2009 influenza A virus in swine herds in Poland. Bull Vet Inst Pulawy 57: 293-300.

Markowska-Daniel I, Wierzchosławski K, Urbaniak K, Kowalczyk A, Pejsak Z (2013b) First case of the isolation of the H1N2 swine influenza virus in Polish pig farm. Bull Vet Inst Pulawy 57: 9-14.

Mehle A, Doudna JA (2008) An inhibitory activity in human cells restricts the function of an avian-like influenza virus polymerase. Cell Host Microbe 4: 111-122.
Mehle A, Doudna JA (2009) Adaptive strategies of the influenza virus polymerase for replication in humans. Proc Natl Acad Sci U S A 106: 21312-21316.

Munster VJ, de Wit E, van den Brand JM, Herfst S, Schrauwen EJ, Bestebroer TM, van de Vijver D, Boucher CA, Koopmans M, Rimmelzwaan GF, Kuiken T, Osterhaus AD, Fouchier RA. (2009) Pathogenesis and transmission of swine-origin 2009 A(H1N1) influenza virus in ferrets. Science 325: 481-483.

Myers KP, Olsen CW, Gray GC (2007) Cases of swine influenza in humans: a review of the literature. Clin Infect Dis 44: 1084-1088.

Nelli RK, Kuchipudi SV, White GA, Perez BB, Dunham SP, Chang KC (2010) Comparative distribution of human and avian type sialic acid influenza receptors in the pig. BMC Vet Res 6: 4.

Oshansky CM, Pickens JA, Bradley KC, Jones LP, Saavedra-Ebner GM, Barber JP, Crabtree JM, Steinhauer DA, Tompkins SM, Tripp RA (2011) Avian influenza viruses infect primary human bronchial epithelial cells unconstrained by sialic acid $\alpha 2,3$ residues. PLoS One 6: e21183.

Reperant LA, Kuiken T, Osterhaus AD (2012) Adaptive pathways of zoonotic influenza viruses: from exposure to establishment in humans. Vaccine 30: 4419-4434.

Reperant LA, Rimmelzwaan GF, Kuiken T (2009) Avian influenza viruses in mammals. Revue Scientifique et Technique 28: 137-159.

Shi WF, Gibbs MJ, Zhang YZ, Zhang Z, Zhao XM, Jin X, Zhu CD, Yang MF, Yang NN, Cui YJ, Ji L (2008) Genetic analysis of four porcine avian influenza viruses isolated from Shandong. China Arch Virol 153: 211-217.

Shinya K, Ebina M, Yamada S, Ono M, Kasai N, Kawaoka Y (2006) Avian flu: influenza virus receptors in the human airway. Nature 440: 435-436.

Steel J, Lowen AC, Mubareka S, Palese P (2009) Transmission of influenza virus in a mammalian host is increased by PB2 amino acids $627 \mathrm{~K}$ or 627E/701N. PLoS Pathog 5: e1000252.

Stevens J, Blixt O, Glaser L, Taubenberger JK, Palese P, Paulson JC, Wilson IA (2006) Glycan microarray analysis of the hemagglutinins from modern and pandemic influenza viruses reveals different receptor specificities. J Mol Biol 355: 1143-1155.

Tarendeau F, Boudet J, Guilligay D, Mas PJ, Bougault CM, Boulo S, Baudin F, Ruigrok RW, Daigle N, Ellenberg J, Cusack S, Simorre JP, Hart DJ (2007) Structure and nuclear import function of the Cterminal domain of influenza virus polymerase PB2 subunit. Nature Structural \& Molecular Biology 14: 229-233.

Taubenberger JK, Kash JC (2010) Influenza virus evolution, host adaptation, and pandemic formation. Cell Host Microbe 7: 440-451.

Thongratsakul S, Suzuki Y, Hiramatsu H, Sakpuaram T, Sirinarumitr T, Poolkhet C, Moonjit P, Yodsheewan R, Songserm T (2010) Avian and human influenza $A$ virus receptors in trachea and lung of animals. Asian Pac J Allergy Immunol 28: 294-301.

Van Poucke SG, Nicholls JM, Nauwynck HJ, Van Reeth K (2010) Replication of avian, human and swine influenza viruses in porcine respiratory explants and association with sialic acid distribution. $V i$ rol J 7: 38 .

Vincent A, Awada L, Brown I, Chen H, Claes F, Dauphin G, Donis $\mathrm{R}$, Culhane $\mathrm{M}$, Hamilton $\mathrm{K}$, Lewis $\mathrm{N}$, Mumford E, Nguyen T, Parchariyanon S, Pasick J, Pavade G, Pereda A, Peiris M, Saito T, Swenson S, Van Reeth K, Webby R, Wong F, Ciacci-Zanella J (2014) Review of influenza A virus in swine worldwide: a call for increased surveillance and research. Zoonoses Public Health 61: 14-17 doi: $10.1111 /$ zph.12049.

Wagner R, Matrosovich M, Klenk HD (2002) Functional balance between haemagglutinin and neuraminidase in influenza virus infections. Reviews in Medical Virology 12: 159-166.

Webster RG, Bean WJ, Gorman OT, Chambers TM, Kawaoka Y (1992) Evolution and ecology of influenza A viruses. Microbiol Rev 56: $152-179$.

Xu C, Fan W, Wei R, Zhao H (2004) Isolation and identification of swine influenza recombinant A/Swine/Shandong/1/2003(H9N2) virus. Microbes Infect 6: 919-925.

Xu C, Hu WB, Xu K, He YX, Wang TY, Chen Z, Li TX, Liu JH, Buchy P, Sun B (2012) Amino acids 473V and 598P of PB1 from an avian-origin influenza $A$ virus contribute to polymerase activity, especially in mammalian cells. J Gen Virol 93: 531-540.

Xu R, McBride R, Paulson JC, Basler CF, Wilson IA (2010) Structure, receptor binding, and antigenicity of influenza virus hemagglutinins from the 1957 H2N2 pandemic. J Virol 84: 1715-1721.

Yan S, Wu G (2010) Evidence obtained from ANOVA to reason cross-species infection and cross-subtype mutation in neuraminidases of influenza A viruses. Transbound Emerg Dis 57: 254-261.

Yu H, Hua RH, Wei TC, Zhou YJ, Tian ZJ, Li GX, Liu TQ, Tong GZ (2008) Isolation and genetic characterization of avian origin H9N2 influenza viruses from pigs in China. Vet Microbiol 131: 82-92. 